\title{
From the Editor's Desk: Publishing in Times of a Pandemic
}

\author{
Pia Raanani \\ Institute of Hematology, Davidoff Cancer Center, Rabin Medical Center, Petah Tikva, Israel
}

Severe acute respiratory syndrome coronavirus 2 (SARS-CoV-2), the cause of coronavirus disease (COVID-19), initiated a global health and economic crisis. Since it first appeared in December 2019 in Wuhan and its declaration as a pandemic by the WHO in March 2020, nearly 115 million people were diagnosed with the disease and more than 2.5 million died of it.

The great scientific achievement of 2020 was the development of several vaccines in less than 1 year. However, the conduct of randomized clinical trials testing treatments for COVID-19 has been less satisfying. Unfortunately, apart from the UK, many countries enrolled only a small fraction of patients with COVID-19 in randomized clinical trials despite the fact that hundreds of them were designed and registered. Thus, there are many anecdotal reports of therapeutic successes with little regard to the effect of unrecognized confounders.

From the hematological perspective, it seems that SARS-CoV-2 infection leads to a whole spectrum of clinical manifestations and associations. These include thromboembolic complications in COVID-19 patients, the controversial role of convalescent plasma, and the special considerations needed for immunocompromised hemato-oncological patients, necessitating a "personalized" approach to treatment and vaccination.
"Everybody knows that pestilences have a way of recurring in the world, yet somehow we find it hard to believe in ones that crash down on our heads from a blue sky. There have been as many plagues as wars in history, yet always plagues and wars take people equally by surprise." (Albert Camus, The Plague).

In 2020, we, in Acta Haematologica, made endeavors to present our readers with timely articles, discussing important hematological perspectives regarding the influence that COVID-19 had on our lives.

Thus, 16 out of 44 submitted manuscripts relating to the COVID-19 pandemic were accepted for publication in 2020. To mention just a few of them: the attitude toward COVID-19 leukemia patients [1], the approach to multiple myeloma patients with COVID-19 [2], thromboembolic complications of the virus [3], RBC distribution as a predictor of severity of COVID-19 infections [4], challenging aspects in CLL patients [5] as well as several editorials $[6,7]$ touching on the hematologist's viewpoint in times of a pandemic.

In general, from 2019 to 2020 Acta Haematologica saw a $44 \%$ increase in the submission of manuscripts. With this respect, our journal follows the general trend seen also in other scientific journals, which could not be attributed solely to articles related to COVID-19. This increase in the number of submissions might be a "fringe benefit" from the several lockdowns we experienced, which enabled our authors to complete and submit their scientific work.

While the increased number of submissions brought more work for our editorial board members and reviewers, it also enabled us to be even more selective with the

Correspondence to:

Pia Raanani, praanani@012.net.il 
acceptance of manuscripts and present our readers with high-quality articles. Thanks to the new peer review software we introduced in 2019, we were able to smoothly handle the increased submission volume. This web-based peer review system enabled us to increase the speed of communication between authors, reviewers, editors, and the editorial office.

Despite the pandemic, we followed our tradition of publishing special issues dedicated to one topic. In 2020, we published a special issue entitled "Light Chain Amyloidosis" edited by Dr. Iuliana Vaxman and Dr. Morie A. Gertz [8] which covered worldwide perspectives of amyloidosis. My sincere thanks to both editors for providing a comprehensive overview on amyloidosis.

There are many people to whom I am grateful for their contribution to the success of this journal: I would like to thank our authors for their ongoing trust and our reviewers for their important contribution. This is also an opportunity to acknowledge all the Karger team members led by Ms. Gabriella Karger, chairwoman of the board of directors. Special thanks to our editorial board members for your invaluable contributions and commitment over the years.

Pia Raanani, editor-in-chief.

\section{Conflict of Interest Statement}

The author has no conflicts of interest to declare.

\section{Funding Sources}

There is no funding of any research relevant to this article.

\section{Author Contributions}

This article was fully contributed by Pia Raanani.

\section{References}

1 Paul S, Rausch CR, Jain N, Kadia T, Ravandi $\mathrm{F}$, DiNardo CD, et al. Treating leukemia in the time of COVID-19. Acta Haematol. 2020 May 11:1-13.

2 Al Saleh AS, Sher T, Gertz MA. Multiple myeloma in the time of COVID-19. Acta Haematol. 2020;143(5):410-6.

3 Tal S, Spectre G, Kornowski R, Perl L. Venous thromboembolism complicated with COVID-19: what do we know so far? Acta Haematol. 2020;143(5):417-24.
4 Lippi G, Henry BM, Sanchis-Gomar F. Red blood cell distribution is a significant predictor of severe illness in coronavirus disease 2019. Acta Haematol. 2020 Aug 25:1-5.

5 Langerbeins P, Eichhorst B. Immune dysfunction in patients with chronic lymphocytic leukemia and challenges during COVID-19 pandemic. Acta Haematol. 2021 Feb 25:1-11.
6 Gale RP. A haematologist's guide to coronavirus disease 2019: encyclopaedia or doorstop? Acta Haematol. 2021;144(1):8-9.

7 Gale RP. Perspective: SARS-CoV-2, COVID-19 and haematologists. Acta Haematol. 2020 May 6:1-4.

8 Vaxman I, Gertz MA. Worldwide perspectives of amyloidosis. Acta Haematol. 2020 143(4):301-3. 